\title{
ATRIBUTOS FÍSICOS DE UM ARGISSOLO E RENDIMENTO DE CULTURAS DE ACORDO COM O REVOLVIMENTO DO SOLO EM PLANTIO DIRETO ${ }^{(1)}$
}

\author{
Alaerto Luiz Marcolan ${ }^{(2)}$ \& Ibanor Anghinoni ${ }^{(3)}$
}

\begin{abstract}
RESUMO
O sistema plantio direto melhora a qualidade estrutural do solo. Entretanto, o tráfego de máquinas pode levar à compactação superficial. Nessa situação, a mobilização para incorporar calcário, ao mesmo tempo que corrige a acidez na camada mobilizada do solo, reduz os possíveis efeitos negativos da compactação. Assim, avaliaram-se os efeitos de mobilizar ou não o solo por ocasião das reaplicações de calcário nos atributos físicos no perfil do solo e no rendimento de culturas em diferentes sistemas e tempos de manejo do solo. $\mathrm{O}$ experimento foi realizado na Estação Experimental Agronômica da UFRGS, em Eldorado do Sul (RS), em um Argissolo Vermelho distrófico típico. Os manejos foram: (a) sistema plantio direto 12 anos, (b) sistema plantio direto oito anos, (c) sistema plantio direto com mobilização do solo para incorporar calcário a cada quatro anos e (d) preparo convencional 12 anos. Quatro anos após a mobilização do solo para a segunda reaplicação de calcário, foram determinados a densidade, a porosidade total, a macroporosidade, a microporosidade, a estabilidade de agregados e o teor de carbono orgânico em três camadas $(0,0-2,5 ; 2,5-7,5$ e $7,5-15,0 \mathrm{~cm}$ ) do solo, bem como a produtividade das culturas de milho e aveia + ervilhaca. O solo já havia recuperado os atributos físicos à condição original após quatro anos de plantio direto. Os atributos físicos do solo foram mais uniformes no perfil no preparo convencional, mas a estabilidade de agregados na camada superficial foi menor em relação ao plantio direto. As diferenças nos atributos físicos do solo decorrentes dos sistemas de manejo não foram suficientes para influir na produtividade das culturas de milho e de aveia + ervilhaca.
\end{abstract}

Termos de indexação: preparo do solo, agregação, milho, aveia + ervilhaca.

\footnotetext{
(1) Parte da Tese de Mestrado do primeiro autor, apresentada ao Programa de Pós-Graduação em Ciência do Solo, Universidade Federal do Rio Grande do Sul - UFRGS. Executada com recursos do Projeto CNPq-PRONEX/Solos. Recebido para publicação em outubro de 2004 e aprovado em dezembro de 2005.

${ }^{(2)}$ Doutorando do Programa de Pós-Graduação em Ciência do Solo, Universidade Federal do Rio Grande do Sul - UFRGS. Av. Bento Gonçalves, 7712. CEP 91540-000, Porto Alegre (RS). E-mail: amarcolan@hotmail.com

${ }^{(3)}$ Professor do Departamento de Solos, UFRGS. Bolsista do CNPq. E-mail: ibanghi@ufrgs.br
} 


\title{
SUMMARY: PHYSICAL ATTRIBUTES OF AN ULTISOL AND CROP YIELD AS AFFECTED BY SOIL MOBILIZATION IN NO-TILLAGE SYSTEM
}

\begin{abstract}
The no-tillage system improves the structural soil quality. However, machinery traffic can cause surface soil compaction. In this situation, soil tilling for lime incorporation not only corrects soil acidity problems, but also decreases possible negative effects of soil compaction. The effects of tilling or not tilling the soil at the moment of lime reapplication on physical attributes in the soil profile and crop yields under different soil management systems were therefore evaluated. A long-term experiment was conducted on a Rhodic Paleudult (Ultisol) at the Agronomical Experimental Station-UFRGS, in Eldorado do Sul, Rio Grande do Sul State, Brazil, during 12, 8 and 4 years under no-tillage and 12 years under conventional systems. The soil physical attributes (bulk density, porosity and aggregate stability) and organic carbon content were evaluated in three $(0-2.5 ; 2.5-7.5$ and $7.5-15.0 \mathrm{~cm})$ soil layers, four years after soil mobilization for lime incorporation. Corn and black oat + vetch yields were also determined. The measured soil physical attributes returned to the original condition after four years under no-tillage. The soil physical attributes were more uniform in the conventional tillage, but with a lower aggregate stability in the surface layer in comparison to the no-tillage treatments. The observed differences in the soil physical attributes were not enough to affect corn and black oat + vetch yields.
\end{abstract}

Index terms: soil tillage, aggregation, corn, oat + vetch.

\section{INTRODUÇÃO}

O sistema plantio direto propicia economia ao sistema de produção de grãos pelo menor número de operações com máquinas agrícolas e diminui a erosão do solo das lavouras, em relação ao preparo convencional. Com a não-mobilização do solo, ocorre um aumento no teor de carbono orgânico total (Lovato et al., 2004) e uma melhoria do estado de agregação e de estabilidade dos agregados (Silva \& Mielniczuk, 1997), condição essencial para garantir alta produtividade agrícola.

Os solos brasileiros, em geral, necessitam de correção da acidez para sua utilização na agricultura. A aplicação superficial de calcário está sendo eficiente na correção da acidez no perfil do solo em lavouras em plantio direto. Os efeitos ocorrem também em subsuperfície (Oliveira \& Pavan, 1996; Rheinheimer et al., 2000; Petrere \& Anghinoni, 2001; Amaral et al., 2004), favorecendo o crescimento vegetal e o rendimento de grãos (Sá, 1996; Pottker \& Ben, 1998; Caires et al., 2000). Diante disso, a aplicação superficial de calcário, sem posterior incorporação ao solo, passou a ser recomendada para a correção da acidez do solo no sistema plantio direto consolidado (CQFS RS/SC, 2004).

A pressão exercida pelo tráfego de máquinas agrícolas necessária ao cultivo pode levar à compactação superficial do solo ao longo do tempo de seu uso no sistema plantio direto (Tormena \& Roloff, 1996). Por outro lado, muitas lavouras da região do Planalto Sulriograndense apresentam solos com problemas de $\mathrm{pH}$ muito elevado $(>7,0)$ na superfície e possíveis problemas de deficiência de micronutrientes, em decorrência da aplicação superficial de calcário sem critério técnico. Em ambas as situações, um eventual revolvimento do solo, ao mesmo tempo que elimina o problema de compactação superficial, mistura o solo superficial, eliminando os problemas relacionados com o $\mathrm{pH}$ elevado e favorece a decomposição da matéria orgânica acumulada na superfície, disponibilizando nutrientes para as culturas. Mesmo considerando esses possíveis benefícios, qualquer mobilização do solo é questionada, principalmente pela falta de informações dos seus efeitos nos atributos físicos do solo, especialmente os relacionados com a sua agregação.

É de se supor que uma mobilização do solo a cada quatro ou cinco anos poderia ser utilizada sem maiores prejuízos à qualidade estrutural do solo, uma vez que seus efeitos seriam muito menores do que os ocasionados em lavouras continuamente utilizadas com preparo convencional. Assim, o que se verificou, em um dos poucos trabalhos desenvolvidos no País (Fucks et al., 1994), é que o preparo convencional (uma aração e duas gradagens), em área com quatro anos de plantio direto, resultou em perda na qualidade estrutural do solo, evidenciada pela redução em 2,2 vezes do diâmetro médio geométrico de agregados, especialmente na classe entre 4,76 e 8,00 mm. Além disso, a recuperação dessa qualidade estrutural mostrou-se lenta, pois, de acordo com Santin et al. (1994), foram necessários três anos para que o mesmo solo recuperasse de 53 a $90 \%$ o diâmetro médio dos agregados. 
A busca de informações que possam permitir a sustentabilidade da produção agrícola e a preservação da qualidade do solo é necessária e deve ser continuada.

Assim, o presente trabalho foi realizado com o objetivo de avaliar os efeitos do revolvimento do solo nos atributos físicos no perfil do solo e seu efeito conjugado ao da incorporação do calcário no rendimento de culturas, em experimento de longa duração envolvendo sistemas de manejo do solo.

\section{MATERIAL E MÉTODOS}

O experimento foi instalado em 1988 na Estação Experimental Agronômica da Universidade Federal do Rio Grande do Sul, no município de Eldorado do Sul (RS), em Argissolo Vermelho distrófico típico (Embrapa, 1999), textura franco-argilo-arenosa.

Em maio de 1988, foram aplicados $3,4 \mathrm{Mg} \mathrm{ha}^{-1}$ de calcário dolomítico (PRNT $100 \%$ ) sobre uma área com pastagem nativa, por 15 anos, para elevar o $\mathrm{pH}$ a 6,0, incorporando-o por meio de uma aração e duas gradagens e, em julho, aveia preta (Avena strigosa S.) foi semeada, objetivando a produção de biomassa para cobertura do solo. Em outubro, antes de estabelecer a cultura do milho (Zea mays, L.), foram aplicados os tratamentos de preparo convencional (uma aração até $17 \mathrm{~cm}$ de profundidade e duas gradagens) e sem preparo (plantio direto). A área experimental foi cultivada por quatro anos com milho, no verão, e aveia preta, no inverno. As adubações de nitrogênio, de fósforo e de potássio para o milho e de nitrogênio para a aveia preta foram efetuadas com base na análise do solo, conforme a Comissão de Fertilidade do Solo (Siqueira et al., 1987; CFS RS/SC, 1995).

Em setembro de 1992, efetuou-se a primeira reaplicação de calcário dolomítico, $3,7 \mathrm{Mg} \mathrm{ha}^{-1}$ (PRNT $100 \%$ ), com o objetivo de elevar o pH a 6,0, tendo sido as parcelas revolvidas, para incorporar o calcário, ou não, de modo a gerar os seguintes tratamentos: (a) sistema plantio direto contínuo por quatro anos, (b) sistema plantio direto antecedido por quatro anos de preparo convencional, (c) preparo convencional no quarto ano, e (d) preparo convencional contínuo por quatro anos. O experimento foi, então, realizado, por mais quatro anos, com mobilização do solo somente nas subparcelas de preparo convencional contínuo. Em outubro de 1996, realizou-se a segunda reaplicação de calcário dolomítico, 2,5 Mg ha-1 (PRNT $100 \%$ ), e, em outubro de 2000, a terceira, $4,1 \mathrm{Mg} \mathrm{ha}^{-1}$ (PRNT $100 \%$ ), seguindo os mesmos procedimentos adotados nas reaplicações anteriores. Assim, nessa ocasião, o experimento apresentava os seguintes tratamentos: (a) sistema plantio direto durante 12 anos, (b) sistema plantio direto durante oito anos, antecedido por quatro anos de preparo convencional, (c) sistema plantio direto durante 12 anos, com revolvimento do solo no quarto e oitavo ano, para incorporar o calcário e (d) preparo convencional durante 12 anos. Esses tratamentos estavam distribuídos de forma casualizada em três blocos.

A partir de 1997, introduziu-se a ervilhaca comum (Vicia sativa) à aveia preta. No ano agrícola em que se fez esta avaliação (1999/00), cultivou-se o híbrido de milho Pioneer 3069. A adubação foi efetuada com base na análise do solo das parcelas de preparo convencional contínuo e a recomendação conforme a CFS RS/SC (1995). O espaçamento dentro da linha foi de $0,2 \mathrm{~m}$ e, entre as linhas, de 1,0 m. A semeadura foi feita com matraca, e a população, após desbaste, era de aproximadamente 50.000 plantas ha-1. Na fase de enchimento de grãos, quatro plantas inteiras foram colhidas para a determinação da matéria seca. Após a colheita para a avaliação do rendimento de grãos $\left(16 \mathrm{~m}^{2}\right.$ por parcela), as plantas de milho foram manejadas com rolo faca para o cultivo de aveia preta + ervilhaca comum (espaçamento entrelinhas de $17 \mathrm{~cm}$ e sulco para semeadura de aproximadamente $2 \mathrm{~cm}$ de profundidade).

Após a avaliação do rendimento de matéria seca de aveia preta + ervilhaca comum $\left(1 \mathrm{~m}^{2}\right.$ por parcela), as plantas foram dessecadas com uma solução que continha $3 \mathrm{~L} \mathrm{ha}^{-1}$ de glifosato e manejadas com rolo faca. Em setembro de 2000, foi feita a amostragem de solo, na camada de $0-15 \mathrm{~cm}$, para sua caracterização, por ocasião da aplicação de calcário, 12 anos após o início do experimento. O solo apresentava os seguintes atributos químicos: $\mathrm{pH}$ $\mathrm{H}_{2} \mathrm{O}=5,06 ; \mathrm{Ca}^{2+}=33,87 \mathrm{mmol}_{\mathrm{c}} \mathrm{dm}^{-3} ; \mathrm{Mg}^{2+}=$ $16,33 \mathrm{mmol}_{\mathrm{c}} \mathrm{dm}^{-3} ; \mathrm{Al}^{3+}=3,86 \mathrm{mmol}_{\mathrm{c}} \mathrm{dm}^{-3} ; \mathrm{K}=$ $3,30 \mathrm{mmol}_{\mathrm{c}} \mathrm{dm}^{-3}$; CTCe $=57,35 \mathrm{mmol}_{\mathrm{c}} \mathrm{dm}^{-3} \mathrm{e} \mathrm{V}=$ $93,14 \%$, todos analisados conforme método descrito em Tedesco et al. (1995).

As amostras de solo para a avaliação dos atributos físicos e de carbono orgânico total foram coletadas com pá-de-corte e anéis volumétricos, em três locais nas entrelinhas do milho de cada parcela, nas profundidades de $0-2,5,2,5-7,5$ e $7,5-15,0 \mathrm{~cm}$. Os atributos avaliados foram: carbono orgânico total, pelo método de Walkley \& Black, conforme Tedesco et al. (1995), densidade de solo, segundo Blake \& Hartge (1986), macroporosidade, microporosidade e porosidade total, segundo Danielson \& Sutherland (1986), usando-se funil com placa porosa de vidro, tensão e sucção matricial de $6 \mathrm{kPa}$, e estabilidade de agregados, com base no método de Kemper \& Chepil (1965), utilizando peneiragem úmida e seca em agregados menores que $9,51 \mathrm{~mm}$ e um conjunto de peneiras, com malhas de 4,$76 ; 2,00 ; 1,00 ; 0,50$ e $0,25 \mathrm{~mm}$.

O índice de estabilidade dos agregados foi obtido pela razão $\mathrm{DMPu} / \mathrm{DMPs}$ (diâmetro médio ponderado obtido pela agitação úmida dividido pelo obtido pela agitação a seco). Informações mais detalhadas são encontradas em Marcolan (2002). 
Realizou-se a análise da variância dos resultados de rendimento do milho e aveia preta + ervilhaca comum, considerando o delineamento experimental de blocos ao acaso, utilizando-se o teste de Tukey $(\mathrm{P}<0,05)$ para a comparação entre médias. A análise de variância para os dados dos atributos físicos foi feita de acordo com o modelo (1) com a inclusão da restrição ao fator profundidade:

$$
\begin{gathered}
\mathrm{Y}_{\mathrm{ij}} \mathrm{k}=\mu+\mathrm{Bi}+\mathrm{Sj}+\text { erro a }(\mathrm{ij})+ \\
+\mathrm{Pk}+\text { erro b (ik) }+ \text { SPjk }+ \text { erro c (ijk) }
\end{gathered}
$$

sendo $\mathrm{B}=$ blocos $(\mathrm{i}=1,2,3) ; \mathrm{S}=$ sistemas de manejo $(\mathrm{j}=1,2,3,4) ; \mathrm{P}=$ profundidade do solo $(\mathrm{k}=1,2,3)$.

\section{RESULTADOS E DISCUSSÃO}

O solo sob plantio direto (4, 8 e 12 anos) apresentou menor densidade na camada superficial $(0-2,5 \mathrm{~cm})$ em relação às demais camadas avaliadas (Figura 1). Em contrapartida, no preparo convencional, esse atributo foi mais homogêneo na camada revolvida.

Deve-se salientar que, apesar das diferenças entre os tratamentos, a densidade do solo é elevada e, conseqüentemente, a porosidade total é baixa (Figura 2), principalmente na camada de 2,5$15,0 \mathrm{~cm}$ nos tratamentos de sistema plantio direto. Os elevados valores de densidade do solo devem-se, provavelmente, à distribuição das partículas do argissolo em estudo (areia $62 \%$, silte $12 \%$ e argila $26 \%$ que, segundo Barnes et al. (1971), predispõe ao adensamento do solo. Assim, as partículas tendem a se ajustar umas nos espaços deixados pelas outras, elevando a densidade do solo e resultando na formação de camadas adensadas, mesmo em solos sem interferência antrópica. No entanto, o sistema plantio direto nem sempre causa aumento na densidade do solo, podendo, inclusive diminuí-la e

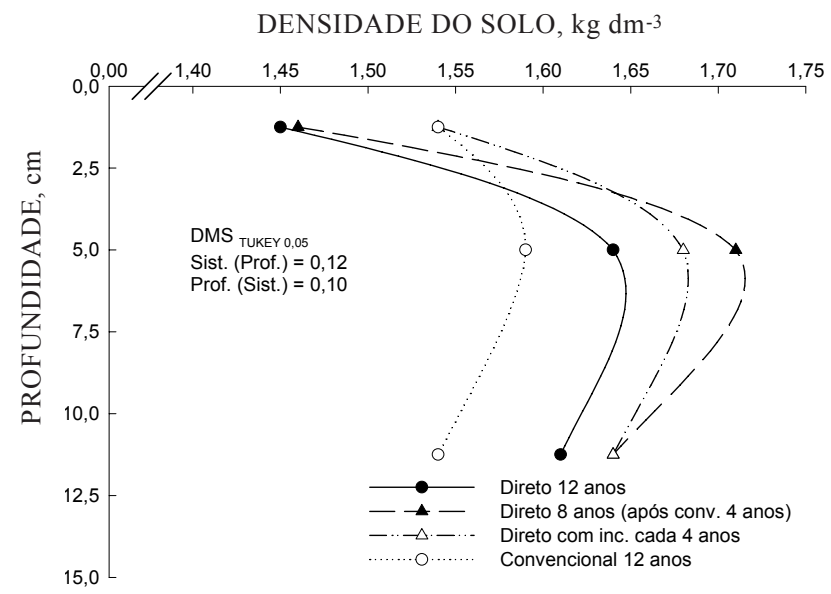

Figura 1. Densidade do solo em diferentes sistemas de manejo e profundidades. aumentar a porosidade e o diâmetro dos agregados, com o passar do tempo de cultivo (Campos et al., 1995).

Como esperado, a porosidade total nos diferentes tratamentos de plantio direto (Figura 2) teve comportamento inverso à densidade (Figura 1). Foi menor na camada superficial do sistema plantio direto por quatro anos, em relação ao plantio direto de oito e 12 anos (Figura 2).

A porosidade total foi maior na camada superficial em relação às demais profundidades em todos os sistemas de manejo. Isso já havia sido observado por Cassol (1995), após quatro anos da instalação do experimento. Diferentemente da camada superficial, o preparo convencional resultou em maior porosidade total na camada de $2,5-7,5 \mathrm{~cm}$, em relação ao plantio direto de quatro e oito anos. Como os valores de porosidade total e densidade do solo no plantio direto de 12 anos se aproximam e não se diferenciam dos de plantio direto de quatro e oito anos, há concordância com a idéia de que, a longo prazo, a qualidade física do solo nesse sistema foi melhorando em profundidade.

O comportamento da macroporosidade (Figura 3) foi similar ao da porosidade total, sendo maior na camada superficial para todos os sistemas de manejo em relação às demais profundidades. Como não houve interação entre sistemas e profundidades para esse atributo físico, verifica-se que o revolvimento do solo a cada quatro anos não resultou em diferença em relação aos sistemas com plantio direto de oito e 12 anos, mas foi menor em relação ao preparo convencional, em que o revolvimento era anual (Figura 3). Observam-se, também, na camada de 2,5-15,0 cm dos tratamentos de plantio direto por quatro e oito anos, valores de macroporosidade menores que $0,10 \mathrm{dm}^{3} \mathrm{dm}^{-3}$. Estes valores podem, segundo Vomocil \& Flocker (1961) e Grable \& Siemer (1968), restringir o crescimento radicular e o desenvolvimento das plantas.

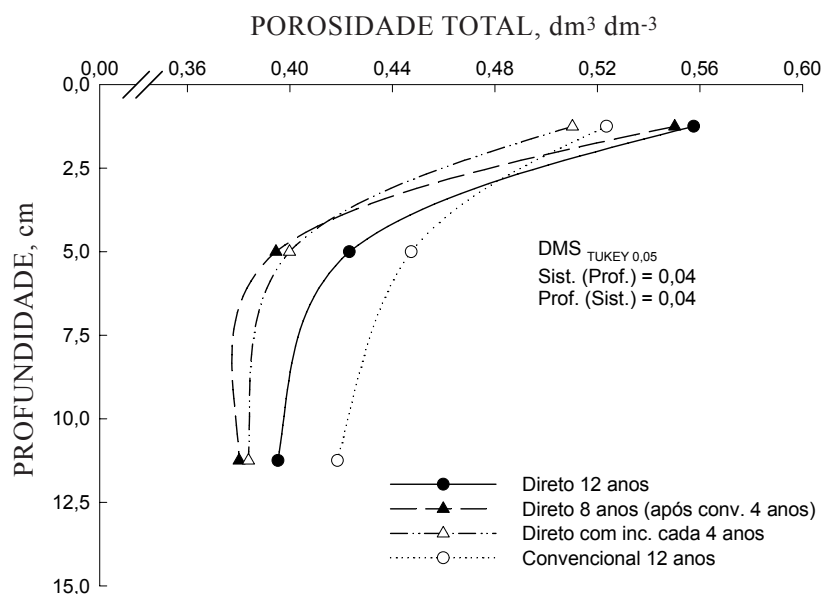

Figura 2. Porosidade total do solo em diferentes sistemas de manejo e profundidades. 
A microporosidade foi também maior na camada superficial nos tratamentos com plantio direto em relação às camadas subsuperficiais (Figura 4). Entretanto, essa diferença não existiu no preparo convencional, uma vez que o revolvimento anual do solo tende a homogeneizá-lo em todo o perfil revolvido. Na comparação entre os tratamentos, houve diferença somente na camada superficial, onde a microporosidade foi menor no preparo convencional em relação aos tratamentos sob plantio direto (Figura 4). É possível que, com o revolvimento anual do solo, ocorra a obstrução dos microporos pelas partículas de argila.

A qualidade do solo pode ser visualizada por meio do índice de estabilidade de agregados (Figura 5). Considerando o método utilizado, quanto maior o valor da relação DMPu/DMPs (mais próximo da unidade), maior é a estabilidade dos agregados do solo.

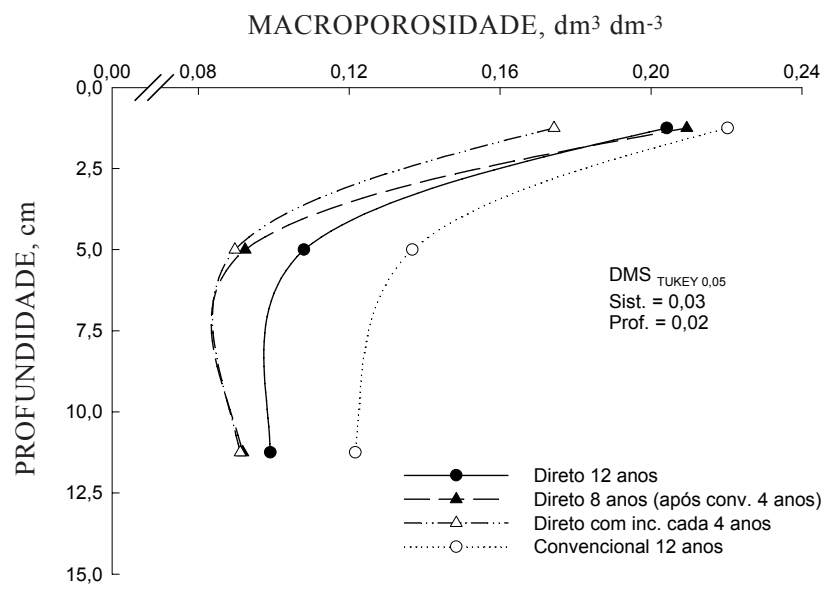

Figura 3. Macroporosidade do solo em diferentes sistemas de manejo e profundidades.

MICROPOROSIDADE, $\mathrm{dm}^{3} \mathrm{dm}^{-3}$

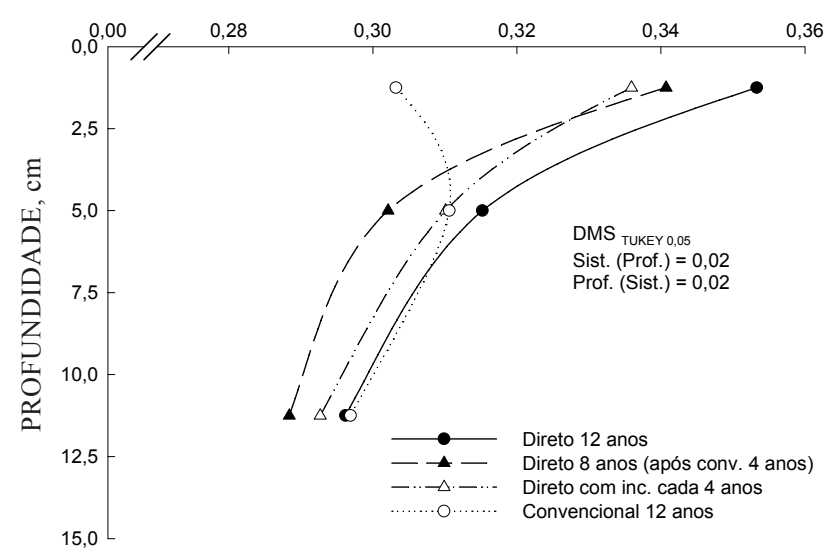

Figura 4. Microporosidade do solo em diferentes sistemas de manejo e profundidades.
O índice de estabilidade de agregados foi maior na camada superficial nos três tratamentos do sistema plantio direto em relação ao preparo convencional (Figura 5). No sistema plantio direto, esse índice decresce em profundidade, especialmente no de 12 anos. O revolvimento do solo cultivado em sistema plantio direto, para a incorporação do calcário, também incorpora agregados mais estáveis presentes na superfície que, somados à incorporação da matéria orgânica, devem elevar a estabilidade em profundidade, com uma conseqüente tendência de diminuição na superfície. Segundo Carpenedo \& Mielniczuk (1990), o sistema plantio direto propicia maior estabilidade de agregados em relação ao preparo convencional, no qual são feitas aração e gradagem, seguidas de gradagem de nivelamento por ocasião do plantio.

De maneira geral, os resultados indicam que, apesar de o eventual revolvimento do solo no sistema plantio direto, para a incorporação de calcário, apresentar certo impacto negativo momentâneo sobre alguns atributos físicos do solo, percebe-se, posteriormente, uma recuperação parcial quando o solo é mantido sem revolvimento.

No preparo convencional, a menor estabilidade de agregados era esperada, uma vez que, devido ao revolvimento anual, os agregados vão diminuindo de tamanho. Assim, além das forças disruptivas da ação mecânica, o solo revolvido fica exposto à desagregação pelo impacto das gotas da chuva que, somado à mineralização da matéria orgânica, diminui a estabilidade dos agregados.

O sistema plantio direto, ao acumular material vegetal na superfície, apresenta maior teor de carbono orgânico nessa camada em relação às demais e, também, em relação ao preparo convencional, que apresenta uma distribuição mais uniforme no perfil do solo (Figura 6), uma vez que é revolvido anualmente.

ÍNDICE DE ESTABILIDADE DE AGREGADOS $\mathrm{DMPu} / \mathrm{DMPs}$

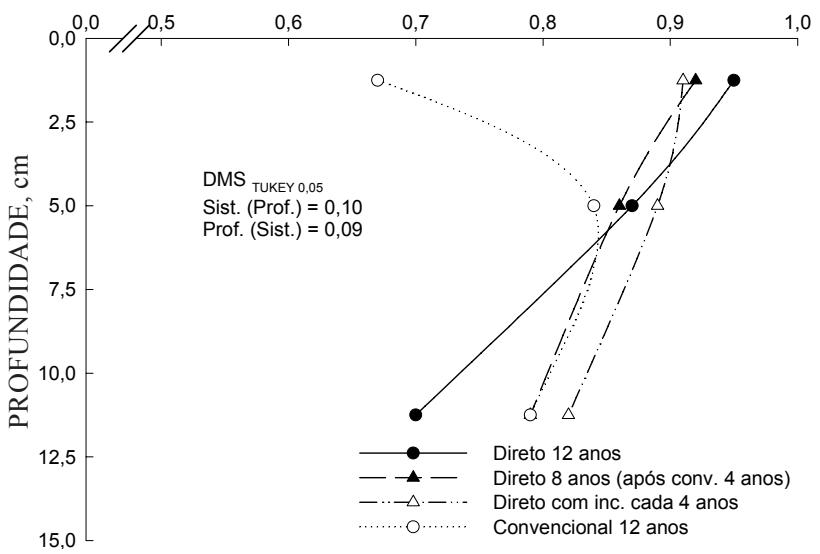

Figura 5. Índice de estabilidade de agregados em diferentes sistemas de manejo e profundidades. 
O teor de carbono orgânico do solo apresenta uma relação muito estreita com o índice de estabilidade de agregados $\left(\hat{y}=-0,3822+0,1438 x-0,0039 x^{2} ; R^{2}\right.$ $=0,87 ; \mathrm{P}<0,05)$, demonstrando a semelhança de comportamento dos resultados obtidos (Figuras 5 e 6). Isto está corroborando as correlações entre os índices de agregação e o teor de carbono orgânico encontradas por Carpenedo \& Mielniczuk (1990) e Castro Filho et al. (1998).

No sistema plantio direto, o revolvimento do solo a cada quatro anos não ocasionou mudanças no teor de carbono orgânico total em relação ao plantio direto contínuo por mais tempo (Figura 6), indicando que um eventual revolvimento, seguido de um retorno ao sistema plantio direto, não ocasionaria grande prejuízo à matéria orgânica. A menor densidade do solo e maior macro, micro e porosidade total na camada superficial do sistema plantio direto em relação às demais camadas pode ser relacionada com o efeito da matéria orgânica acumulada na superfície do solo.

Os sistemas de manejo influenciam diretamente as propriedades estruturais do solo, uma vez que a agregação depende, dentre outras coisas, do conteúdo e tipo de matéria orgânica, sistemas de culturas (Perfect et al., 1990), atividade biológica

\section{CARBONO ORGÂNICO TOTAL, $\mathrm{g} \mathrm{kg}^{-1}$}

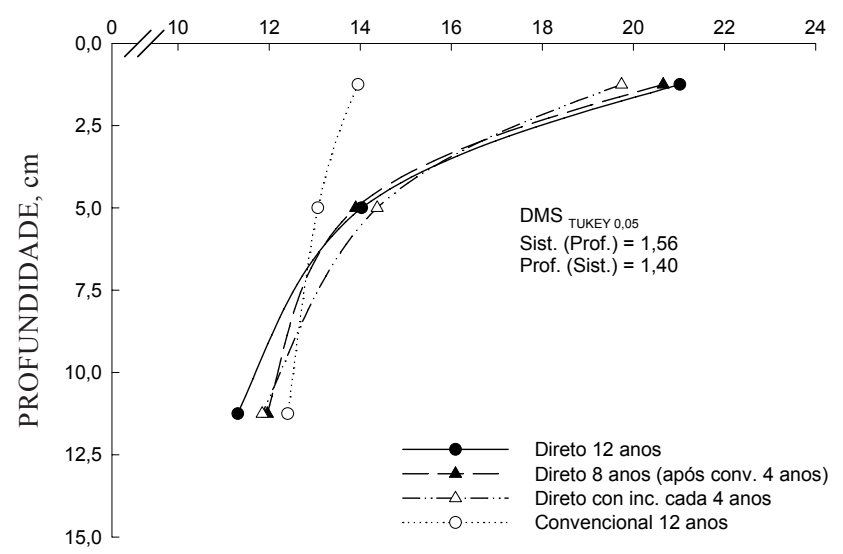

Figura 6. Carbono orgânico total do solo em diferentes sistemas de manejo e profundidades.
(Lehrsch \& Jolley, 1992), preparo do solo e tráfego de máquinas (Kay, 1990) e, ainda, de variações de umidade e temperatura no solo. Deve-se salientar que a instalação do experimento em estudo foi em solo com pastagem natural, com boa estrutura, ao contrário da maioria das lavouras em plantio direto que tem partido de uma estrutura degradada de solo. Outro fato a considerar é que a declividade do terreno no experimento é quase nula e, com isso, eventuais problemas com erosão são mínimos mesmo quando ocorre a mobilização de solo. Também, neste experimento, o tráfego de máquinas era mínimo, uma vez que, a semeadura do milho era feita com "matraca" e a colheita era manual.

As boas condições estruturais do solo no início do experimento, o reduzido trânsito de máquinas e as operações de preparo realizadas em condições privilegiadas de umidade beneficiam os atributos físicos do solo. Em condições de lavoura, certamente o comportamento deve ser diferenciado. Assim, no sistema plantio direto contínuo (12 anos), os atributos físicos avaliados pouco se diferenciaram, em relação ao seu estado original. Bayer (1996) obteve, nas mesmas condições de solo e vegetação, em área próxima, valores de densidade do solo entre 1,49 e 1,63 kg dm${ }^{-3}$ e Silva (1993) de teor de carbono orgânico igual a $20,9 \mathrm{~g} \mathrm{~kg}^{-1}$, na camada de $0-15 \mathrm{~cm}$, semelhantemente aos valores encontrados para o sistema plantio direto por 12 anos.

Os resultados deste trabalho indicam que um possível prejuízo de revolver o solo, para a incorporação do calcário, é passageiro, uma vez que, após quatro anos, essa estabilidade de agregados já estava recuperada. Deve-se salientar que essa recuperação na estabilidade de agregados talvez ocorra em menor período de tempo.

O rendimento de matéria seca e de grãos de milho e o rendimento de aveia preta + ervilhaca comum quatro anos após a reaplicação de calcário não foram afetados pelos diferentes sistemas de manejo do solo (Quadro 1). É possível verificar uma tendência positiva no crescimento do milho quando o solo foi revolvido a cada quatro anos, provavelmente, em virtude da ação do calcário em uma camada maior

Quadro 1. Rendimento ${ }^{(1)}$ de milho e de uma mistura forrageira quatro anos após a segunda reaplicação de calcário em diferentes sistemas de manejo

\begin{tabular}{|c|c|c|c|}
\hline \multirow{2}{*}{ Manejo } & \multicolumn{2}{|c|}{ Milho } & \multirow{2}{*}{$\begin{array}{c}\text { Aveia + ervilhaca } \\
\text { Matéria seca }\end{array}$} \\
\hline & Matéria seca & Grão & \\
\hline & & Mg ha-1 & $\underline{-}$ \\
\hline Direto 12 anos & 10,01 & 8,51 & 5,47 \\
\hline Direto 8 anos (após conv. 4 anos) & 10,36 & 7,64 & 5,32 \\
\hline Direto com inc. de calcário cada 4 anos & 12,21 & 8,99 & 5,26 \\
\hline Convencional 12 anos & 10,12 & 8,96 & 5,44 \\
\hline
\end{tabular}

(1) Não-significativo $(\mathrm{P}>0,05)$. 
do solo e da incorporação dos resíduos orgânicos. Entretanto, essa tendência não se manifestou no rendimento de grãos.

Apesar das diferenças nos atributos físicos no perfil do solo, determinadas pelo revolvimento ou não do solo, nas reaplicações de calcário, os rendimentos encontrados foram além de similares, elevados em todos os sistemas de manejo. Os valores baixos de macroporosidade $\left(<0,10 \mathrm{dm}^{3} \mathrm{dm}^{-3}\right)$, principalmente no sistema sob plantio direto (Figura 3), também não interferiram no crescimento das plantas. Assim, possivelmente, a baixa macroporosidade deve-se à própria condição original do solo, principalmente à textura deste solo que, segundo Barnes et al. (1971), é das mais propícias ao adensamento do solo.

De maneira geral, os bons rendimentos deveramse à ausência de limitações ao desenvolvimento das plantas, independentemente do sistema de manejo. As boas condições encontradas pelos atributos físicos do solo e as condições ambientais favoráveis propiciaram rendimentos semelhantes e adequados.

\section{CONCLUSÕES}

1. O uso do solo no sistema plantio direto por um período de quatro anos após o revolvimento foi suficiente para o retorno dos atributos físicos do solo à condição original, uma vez que eles não se diferenciaram dos do sistema plantio direto de oito e 12 anos.

2. Os atributos físicos apresentaram maior uniformidade no preparo convencional, com tendência de melhoria na porosidade, porém com menor estabilidade de agregados na camada superficial, que foi relacionada com o teor de carbono orgânico.

3. As diferenças nos atributos físicos do solo decorrentes do revolvimento ou não do solo nos diferentes sistemas de manejo do solo não foram suficientes para influir na produtividade de milho e da mistura aveia + ervilhaca.

\section{LITERATURA CITADA}

AMARAL, A.S.; ANGHINONI, I.; HINRICHS, R. \& BERTOL, I. Movimentação de partículas de calcário no perfil de um Cambissolo em plantio direto. R. Bras. Ci. Solo, 28:359-367, 2004.

BARNES, K.X.; CARLETON, W.M.; TAYLOR, H.M.; THROCKMORTON, R.T. \& van den BERG, G.E. Compaction of agricultural soils. Saint Joseph: America Society Agriculture Engineering, 1971. 471p.

BAYER, C. Dinâmica da matéria orgânica em sistemas de manejo de solos. Porto Alegre, Universidade Federal do Rio Grande do Sul, 1996. 240p. (Tese de Doutorado)
BLAKE, G.R. \& HARTGE, K.H. Bulk density. In: KLUTE, A., ed. Methods of soil analysis - physical and mineralogical methods. 2.ed. Madison, American Society of Agronomy, Soil Science Society of America, 1986. p.363-375.

CAIRES, E.F.; BANZATTO, D.A. \& FONSECA, A.F. Calagem na superfície em sistema plantio direto. R. Bras. Ci. Solo, 22:161-169, 2000.

CAMPOS, B.C.; REINERT, D.J.; NICOLODI, R.; RUEDELL, J. \& PETRERE, C. Estabilidade estrutural de um Latossolo Vermelho-Escuro distrófico após sete anos de rotação de culturas e sistemas de manejo de solo. R. Bras. Ci. Solo, 9:121-126, 1995.

CARPENEDO, V. \& MIELNICZUK, J. Estado de agregação e qualidade de agregados de Latossolos Roxos, submetidos a diferentes sistemas de manejo. R. Bras. Ci. Solo, 14:99-105, 1990.

CASSOL, L.C. Características físicas e químicas do solo e rendimento de culturas após a reaplicação de calcário, com e sem incorporação, em sistemas de preparo. Porto Alegre, Universidade Federal do Rio Grande do Sul, 1995. 97p. (Tese de Mestrado)

CASTRO FILHO, C.; MUZILLI, O. \& PODANOSCHI, A.L. Estabilidade dos agregados e sua relação com o teor de carbono orgânico num Latossolo Roxo distrófico, em função de sistemas de plantio, rotações de culturas e métodos de preparo das amostras. R. Bras. Ci. Solo, 22:527-538, 1998.

COMISSÃO DE FERTILIDADE DO SOLO - CFSRS/SC. Recomendações de adubação e de calagem para os estados do Rio Grande do Sul e Santa Catarina. 3.ed. Passo Fundo, Embrapa-CNPT / SBCS - Núcleo Regional Sul, 1995. 223p.

COMISSÃO DE QUÍMICA E FERTILIDADE DO SOLO CFQISRS/SC. Manual de adubação e de calagem para os estados do Rio Grande do Sul e de Santa Catarina. Porto Alegre, SBCS - Núcleo Regional Sul, 2004.

DANIELSON, R.E. \& SUTHERLAND, P.L. Porosity. In: KLUTE, A., ed. Methods of soil analysis - physical and mineralogical methods. 2.ed. Madison, American Society of Agronomy, 1986. p.443-461.

EMPRESA BRASILEIRA DE PESQUISA AGROPECUÁRIA EMBRAPA. Sistema brasileiro de classificação de solos. Rio de Janeiro, Embrapa Solos, 1999. 412p.

FUCKS, L.F.; REINERT, D.J.; CAMPOS, B.C.; BORGES, D.F. \& SCAPINI, C. Degradação da estabilidade estrutural pela aração e gradagem de solo sob plantio direto por quatro anos. In: REUNIÃ̃O BRASILEIRA DE MANEJO E CONSERVAÇÃO DO SOLO E DA ÁGUA, 10., Florianópolis, 1994. Anais. Florianópolis, Sociedade Brasileira de Ciência do Solo, 1994. p.196-197.

GRABLE, A.R. \& SIEMER, E.G. Effects of bulk density, aggregate size, and soil water suction on oxygen difussion, redox potentials, and elongation of corns roots. Soil Sci. Soc. Am. Proc., 32:180-186, 1968.

KAY, B.D. Rates of change of soil structure under different cropping systems. Adv. Soil Sci., 12:1-41, 1990.

KEMPER, W.D. \& CHEPIL, W.S. Size distribution of aggregates. In: BLAKE, C.A., ed. Methods of soil analysis. Madison: American Society of Agronomy, 1965. p.499-510. 
LEHRSCH, G.A. \& JOLLEY, P.M. Temporal changes in wet aggregate stability. Trans. Am. Soc. Agric. Eng., 35:493498, 1992.

LOVATO, T.; MIELNICZUK, J.; BAYER, C. \& VEZZANI, F. Adição de carbono e nitrogênio e sua relação com os estoques no solo e com o rendimento do milho em sistemas de manejo. R. Bras. Ci. Solo, 28:175-187, 2004.

MARCOLAN, A.L. Atributos físicos e químicos de um Argissolo e rendimento de culturas em função do seu revolvimento na reaplicação de calcário no sistema plantio direto. Porto Alegre, Universidade Federal do Rio Grande do Sul, 2002. 76p. (Tese de Mestrado)

OLIVEIRA, E.L. \& PAVAN, M.A. Control of soil acidity in notillage system for soybean production. Soil Till. Res., 38:47$57,1996$.

PERFECT, E.; KAI, B.D.; VAN LOON, W.K.P.; SHEARD, R.W. \& POJASOK, T. Rates chang in soil structural stability under forages and corn. Soil Sci. Soc. Am. J., 54:179-186, 1990.

PETRERE, C. \& ANGHINONI, I. Alteração de atributos químicos no perfil do solo pela calagem superficial em campo nativo. R. Bras. Ci. Solo, 25:885-895, 2001.

PÖTTKER, D. \& BEN, J.R. Calagem em solos sob plantio direto e em campos nativos do Rio Grande do Sul. In: NUERNBERG, N.J., ed. Conceitos e fundamentos do sistema plantio direto. Lages, SBCS-Núcleo Regional Sul, 1998. p.77-92.

RHEINHEIMER, D.S.; SANTOS, E.J.S.; KAMINSKI, J.; BORTOLUZZI, E.C. \& GATIBONI, L.C. Alterações de atributos do solo pela calagem superficial e incorporada a partir de pastagem natural. R. Bras. Ci. Solo, 24:797-805, 2000.
SÁ, J.C.M. Calagem em solos sob plantio direto na região dos Campos Gerais, Centro-Sul do Paraná. In: SÁ, J.M., ed. Curso sobre manejo do solo no sistema plantio direto. Ponta Grossa, Fundação ABC, 1996. p.73-107.

SANTIN, C.; REINERT, D.J.; CAMPOS, B.C. \& GENEZINI, F. Ação do preparo convencional sobre a agregação do solo em área anteriormente cultivada sob plantio direto. In: REUNIÃO BRASILEIRA DE MANEJO E CONSERVAÇÃO DO SOLO E DA ÁGUA, 10., Florianópolis, 1994. Anais. Florianópolis, Sociedade Brasileira de Ciência do Solo, 1994. p.270-271.

SILVA, A.S. Formação, estabilidade e qualidade de agregados do solo afetados pelo uso agrícola. Porto Alegre, Universidade Federal do Rio Grande do Sul, 1993. 126p.(Tese de Doutorado)

SILVA, I.F. \& MIELNICZUK, J. Avaliação do estado de agregação do solo afetado pelo uso agrícola. R. Bras. Ci. Solo, 21:313-319, 1997.

SIQUEIRA, O.F.; SCHERER, E.G.; TASSINARI, G.; ANGHINONI, I.; PATELLA, I.F.; TEDESCO, M.J.; MILAN, P.A. \& ERNANI, P.R. Recomendações de adubação e calagem para os estados do Rio Grande do Sul e Santa Catarina. Passo Fundo, Embrapa/CNPT, 1987. 100p.

TEDESCO, M.J.; GIANELLO, C.; BISSANI, C.; BOHNEN, H. \& VOLKWEISS, S.J. Análise de solo, plantas e outros materiais. 2.ed. Porto Alegre, Universidade Federal do Rio Grande do Sul, 1995. 174p. (Boletim Técnico, 5)

TORMENA, C.A. \& ROLOFF, G. Dinâmica da resistência à penetração de um solo sob plantio direto. R. Bras. Ci. Solo, 20:333-339, 1996

VOMOCIL, J.A. \& FLOCKER, W.J. Effect of soil compaction on storage and movement of soil air and water. Trans. Am. Soc. Agric. Eng., 4:242-246, 1961. 